Torsten Wilholt

\title{
Lost on the Way from Frege to Carnap: How the Philosophy of Science Forgot the Applicability Problem
}

[Manuscript version. The original publication is forthcoming in Grazer philosophische Studien 73, 2006.]

\begin{abstract}
This paper offers an explanation of how philosophy of science in the second half of the $20^{\text {th }}$ century came to be so conspicuously silent on the problem of how to explain the applicability of mathematics. It examines the idea of the early logicists that the analyticity of mathematics accounts for its applicability, and how this idea was transformed during Carnap's efforts to establish a consistent and substantial philosophy of mathematics within the larger framework of Logical Empiricism. I argue that at the end point of this development, philosophical discussion of the applicability problem was terminated although important aspects of the logicists' original response to the applicability problem had had to be sacrificed along the way.
\end{abstract}

\section{The Applicability Problem}

It is a curious fact that the question of why mathematics is applicable in the natural sciences has received so little attention in post-war philosophy of science. Early in the $20^{\text {th }}$ century, the situation was quite different. The applicability problem was at least superficially addressed by many thinkers, and it was frequently regarded as a phenomenon that stands in need of philosophical explanation. As witness, let me quote from a lecture course given by David Hilbert in 1919. (The choice of witness is, of course, not arbitrary, as we shall see before long.)

We are confronted with the peculiar fact that matter seems to comply well and truly to the formalism of mathematics. There arises an unforeseen unison of being and thinking, which for the present we have to accept like a miracle. (Hilbert 1992 [1919/20], 69)

It is evident that the applicability problem did not make it into the canon of established questions of professionalized post-war philosophy of science. Temporally, its disappearance coincided with the ascent and heyday of Logical Positivism and Logical Empiricism. This observation alone would lead us nowhere but to another instance of a much used but feeble rule of thumb in folk HOPOS: Whenever anything seems to have gone wrong in philosophy of science, blame it on Logical Empiricism. (For the benefit of the uninitiated, 
HOPOS is the History of the Philosophy of Science, as in the homonymous international society, cf. http://cas.umkc.edu/scistud/hopos/.)

However, in the case of the applicability problem, it is more than just temporal coincidence that points toward a connection of its disappearance with the rise of logical positivism: One of the most widely known tenets of logical positivism, namely the thesis that mathematics is a body of analytic truths, was often taken to neatly explain why mathematics is applicable. If this explanation was widely believed by adherents and sympathizers of Logical Empiricism, that would explain why the applicability problem received so little consideration: It was abandoned because it was considered solved.

In this paper, I want to propose a way in which this idea can be tracked from its logicist origins to mature (Carnapian) Logical Empiricism. I will also argue that in the course of the transformations that the basic idea underwent, an important aspect of its original explanatory potential with regard to the applicability problem was lost. At the end-point of this development, the applicability problem was excluded from the realm of relevant and sensible theoretical discussion, while at the same time the original logicist contribution to its solution had had to be sacrificed.

But to begin with the beginning, let us first have a look at one relatively early articulation of the idea that the analyticity of mathematics accounts for its applicability. It is taken from a paper of Hans Hahn titled 'Logik, Mathematik und Naturerkennen', published in 1933 in the Vienna Circle's book series Einheitswissenschaft. The title of the paper is significant, because it evidently mirrors that of a paper by David Hilbert, 'Naturerkennen und Logik', published in the journal Naturwissenschaften in 1930, where Hilbert repeats the statement from the 1919 lecture course that was quoted above. In a section bearing the headline: 'Mathematics and Reality', Hahn describes what he calls "the tautological character of mathematics":

That we can put forward the sentence $2+3=5$ apodictically and with universal validity, that we can say with complete certainty even before we perform an observation that it will not show that $2+3=7$, is founded in the fact that by $2+3$ we mean the same as by $5[\ldots]$. [...] The use is again based on the fact that we do not, e.g., see right away that by $24 \times 31$ we mean the same as by 744 ; but if we calculate the product $24 \times 31$, we transform it step by step, in such a way that we are aware during every single transformation that due to the agreements about the use of the occurring signs [...] we still mean the same after the transformation as before the transformation, until finally we have become aware that by $24 \times 31$ we mean the same as by 744 . (Hahn 1988 [1933], 158)

A little later he proceeds: 
And now one should realize how vastly far apart our view is from the old-maybe one may say platonizing-view that the world is constructed according to the laws of logic and mathematics [...] and that with our thinking [...] we have been given a means to grasp these eternal laws of the world. No! It is no reality that our thinking can grasp, no fact of the world that thinking can bring us lore about; it only refers to the way we talk about the world; it can only transform tautologically what has been said. (Ibid., 160) ${ }^{1}$

The tautological character of mathematical statements is here adduced as evidence that worries about the relation between mathematics and the world are misguided. The general stance expressed in these paragraphs is of course not just Hahn's private opinion, neither is it exclusively Viennese. Passages very close to this one can, for example, be found in Ayer's Language, Truth and Logic (1971 [1936], ch. 4).

\section{Logicism and the applicability of mathematics}

What Hahn calls, in Wittgensteinian terminology, the tautological character of mathematics is of course the heritage of the doctrine of logicism in the philosophy of mathematics. The logicists themselves, Frege and Russell in particular, were seriously interested in the applicability of mathematics. As Frege formulated it in the Grundgesetze, it is the applicability of mathematical signs that requires them to have cognitive content ("Gedankeninhalt").

Without cognitive content, no application will be possible. Why can one not get an application of a formation of chess-pieces? Obviously because it does not express a thought. [...] Why can one get applications of arithmetical equations? Only because they express thoughts. [...] Now it is application alone that elevates arithmetic beyond a game to the rank of a science. So applicability necessarily belongs to it. (Frege 1962 [1893/1903], 2:100)

Frege thus makes it clear that the reason to look for cognitive content in mathematical expressions is to attain an explanation why mathematics is useful in a way that a mere game could not be. Russell gets to the point in a down-toearth manner:

[W]e want our numbers to be such as can be used for counting common objects, and this requires that our numbers should have a definite meaning, not merely that they should have certain formal

1 The passages quoted are my translations from the original. An English translation of the complete essay can be found in McGuinness (ed.) 1987, 24-45. 
properties. This definite meaning is defined by the logical theory of arithmetic. (Russell 1993 [1919], 10)

As is well known, the logicists supplied the necessary "definite meaning" or "cognitive content" by means of a definition of mathematical concepts in terms of what were taken to be logical concepts. In Frege's original version, e.g., positive whole numbers are applicable to concepts, such that for every concept $F$, the number of $F^{\prime}$ s is identical with the extension of the concept "equinumerous with $F$ ", where "equinumerous" is in turn definable in terms of a one-to-one correspondence between extensions of concepts.

Assuming that the theory of extensions of concepts is a part of logic, arithmetic is thereby defined in logical terms. Arithmetical truths are logical truths and thus, a fortiori, analytical truths. The version of Russell and Whitehead, though couched in terms of classes and types rather than extensions of concepts, also pursued these same objectives.

Did the Logical Empiricists' absorption of logicistic ideas have anything to do with the concern for applicability? It certainly did for one of the main sponsors of logicism within the movement, namely Rudolf Carnap. In his 1930 paper 'Die Mathematik als Zweig der Logik', where he promotes logicistic philosophy of mathematics against its formalistic alternative, we read the following:

On the other hand, however, the logicistic judge discovers a gap in the system of formalism as it exists so far. As we noticed already about Frege's basic idea, logicism directs its attention especially to the fact that mathematics must be applicable to reality. (Carnap 1930, 309)

He goes on to explain that in order to account for the applicability of mathematics, the mathematical signs must be equipped with meanings, namely purely logical ones. This defense of logicism thus mirrors directly the one expressed by Frege in his vivid comparison of numbers with formations of chess pieces. Logicism is to be favored over formalism because it explains applicability.

\section{The demise of reductive logicism}

As is well known, the logicist reduction of mathematical to logical terms did not enjoy a happy fate. Frege's theory of extensions of concepts turned out to be inconsistent, and its successors and candidates for substitutes-theories of types and axiomatic set theories-all displayed the same deficiency: They all contained premises or axioms that could not reasonably be taken to represent purely logical truths. Carnap himself showed, in his Abriss der Logistik (1929, cf. esp. §9d), how to get around the problematic axiom of reducibility from the Principia Mathematica, but the axiom of infinity and the axiom of choice 
remained stubborn obstacles to any attempt to view mathematical truths as reducible to logical ones.

As we have seen, this reduction was the core of the original logicist explanation of the applicability of mathematics. So how could the view that the applicability problem was no longer a problem survive the demise of reductive logicism? To answer this question, it is advisable to look at the account of that empiricist who paid the most scrupulous attention to the intricacies of such questions, i.e., again, Carnap.

Carnap arrived at the position offered in The Logical Syntax of Language that amounts to a relativization of logic, called, by himself, the principle of tolerance. There is not one authoritative logic, but many possible logics. "Everyone is at liberty to build up his own logic, i.e. his own form of language, as he wishes." (Carnap 1967 [1934], 52) Among these possible forms of language, there are also ones that contain the controversial axioms. Carnap formulates the rules and principles of one such language, language II. The axiom of infinity is made redundant by the syntax of number expressions adopted, and the axiom of choice is explicitly included in the transformation rules of language II in form of a Grundsatz or primitive sentence (primitive sentence PSII 21, ibid., §30, p. 92).

As Alan Richardson has stressed, Carnap's approach amounts to an abandonment of the idea of a reduction of mathematics to pure logic (Richardson 1994, 76). In fact, as Carnap himself explicitly notes, there is not even a clear distinction between logic and mathematics in his view. Both are equally constitutive of a form of language. The truths of mathematics are therefore not logical truths in a Fregean sense, but they are nevertheless analytic. Much could (and has of course) been said about Carnap's concept of analyticity; at this point we may rest content with the notion that for Carnap, mathematical truths were true in virtue of our adoption of a form of language, or, as he was later to call it, a linguistic framework (Carnap 1956 [1950]).

\section{What happened to the applicability problem?}

The title of my paper insinuates that in the development of the logicist idea I have just sketched, something of significance for the applicability problem was lost. I will now attempt to make this claim more precise. On one level, the Logical Empiricist version of logicism as developed by Carnap manages to retain an important ingredient of the Fregean idea. In Carnap's terms, the ingredient in question is the claim that for arithmetical sentences, no question of validity can arise (cf. Carnap 1967 [1934], §25). They are true in virtue of the language we have adopted. So, the question: "What makes arithmetical sentences true?" receives the answer: "The fact that they are analytic truths", 
quite in the manner suggested by Hahn. This is close to Frege's own answer: "The fact that they are analytic truths (that are ultimately logical truths)."

But Frege's reductive idea had additional explanatory potential when it comes to the phenomenon of the universal applicability of arithmetic. From Frege's reduction it follows that arithmetic is applicable wherever concepts are applicable (and have finite extension). Presumably, this is a gain for the explanation of applicability. More precisely, for Frege it is not the things falling under the concepts that arithmetic gets applied to, but the concepts themselves:

The laws of number, therefore, are not really applicable to external things; they are not laws of nature. They are, however, applicable to judgements holding good of things in the external world: they are laws of the laws of nature. (Frege 1980 [1884], 99)

Frege's original version of logicism thus also provides an answer to the question: "Why is arithmetic applicable?" The answer is:

(A-F) Arithmetic is applicable because it is a body of useful truths about concepts of finite extension; and we apply concepts whenever we make judgments about the external world; and a great many of them have finite extensions.

This is an answer that goes far beyond the mere claim that arithmetical truths are analytic.

Analyticity alone does explain why an application of a sentence can never do any harm; it explains why, regardless of what the world is like, you can always add that sentence to a given body of truths and never thereby produce any falsehoods. But applicability, of course, requires more than doing no harm. Mere analyticity does not explain why the statements classified as analytic are of any use in the overall system of knowledge.

The best that the Carnapian would have to offer for an answer to the question "Why is arithmetic applicable?" would be:

(A-C) Arithmetic is applicable because language II is a serviceable language to adopt.

If this seems a weaker answer than the one given on Frege's behalf, it is because in this case the answer seems suspiciously to need an explanation itself. To this observation it might be objected that to ask Carnap: "Why is language II a serviceable language to adopt?" would be the same as to ask Frege "Why do we always use concepts when we relate to the external world?"

But the difference between these two questions is remarkable, or rather: it would have been remarkable, had the Fregean version managed to live up to its promises. The universal applicability of concepts is a matter that one may plausibly accept as a brute fact, as part of the validity of pure logic. In contrast, 
the usefulness of language II, a system that explicitly incorporates a good deal of sophisticated mathematical content (like the axiom of choice), is no more acceptable as a brute fact than the applicability of arithmetic itself.

The Carnap who wrote, in 1950, 'Empiricism, Semantics and Ontology' would probably have scorned the question why language II is a serviceable language to adopt, insisting as he did that questions about the acceptance of a linguistic framework are practical rather than theoretical. Philosophers who ask, e.g.: "Are there numbers?" are not asking a question that could possibly receive any reasonable answer in so far as they intend to ask an external question, i.e. one that is meant to be a question prior to the acceptance of the number framework. He comments:

Unfortunately, these philosophers have so far not given a formulation of their question in terms of the common scientific language. Therefore our judgment must be that they have not succeeded in giving to the external question and to the possible answers any cognitive content. Unless and until they supply a clear cognitive interpretation, we are justified in our suspicion that their question is a pseudo-question, that is, one disguised in the form of a theoretical question while in fact it is non-theoretical; in the present case it is the practical problem whether or not to incorporate into the language the new linguistic forms which constitute the framework of numbers. (Carnap 1956 [1950], 209)

It should be noted that the question whether to adopt the number language is not discredited by Carnap. But his judgment that this question is practical rather than theoretical implies that it calls for a practical decision and not for a verdict in terms of truth (cf. Bird 2003). A theoretical account of the reasons why the number language should be adopted is therefore out of place.

This means that from the mature Carnapian perspective, the applicability problem was dropped from the philosophical canon, not because it was considered to have received an answer, but because all matters of applicability of frameworks were considered practical questions. A theoretical account of the applicability of mathematics was thereby ruled out as inappropriate.

\section{The choice between the reductive and the logicist content of the original idea}

Once we discuss the development of the idea that the analyticity of mathematics accounts for its applicability, we must of course acknowledge that this process has brought undeniable philosophical progress. After all, the original ideas of Frege and Russell were stricken with a contradiction that doomed at least their version of the logicist project. Carnap showed how a position can be achieved that avoids the pitfalls of reductive logicism while 
preserving a compelling account of what it is that makes mathematical statements true.

One might want to leave it at that and claim that Carnap's achievement was truly a success story. Maybe Carnap had just shown that there never was anything to explain with regard to applicability, i.e.: Maybe, abstracting form the illusionary pretense to a "pure logic", Frege's answer (A-F) was no easier to accept as a brute fact and thus no more explanatory than the Carnapian (A-C).

In this last section, I would like to suggest that there is an aspect to the applicability problem and some of the Fregean ideas relating to its solution that was not automatically made obsolete by the demise of reductive logicism. Losing sight of this aspect is really what marks the loss that this paper's title alludes to. This can best be made plausible if we consider the case of real analysis instead of arithmetic.

Frege started on a theory of real numbers that remains fragmentary, because he abandoned the project after having seen the failure of his logicist reduction of arithmetic due to Russell's paradox. But the basic ideas are well established in the account he published in the second volume of Grundgesetze (Frege 1962 [1893/1903] esp. §73 and §§158-164).

As in the case of whole numbers, Frege looked out for the meaning of real numbers that makes them useful for applications. He dismissed the idea proposed by Hermann von Helmholtz (1971 [1887]), that real numbers in scientific applications do not have a meaning by themselves, but form hybrid expressions together with names of units of measurement-the so-called "named numbers" - where only the composite named numbers as a whole serve to refer to magnitudes. (In fact he remarked about Helmholtz's paper: "Hardly anything has ever felt more unphilosophical to me than this philosophical essay, and the sense of the epistemological question has hardly ever been more misconceived than here." Frege 1962 [1893/1903], 2:139, footnote 2. Cf. also ibid., 2:85, footnote 2.) Again, the number expressions themselves must have definite meaning.

Now what does the numeral mean by itself? Obviously a ratio of magnitudes. [...] If now by "number" we understand the meaning of a numeral, then real number is the same as ratio of magnitudes. [...] We will not say anymore that a number or a numeral signifies now a length, now a mass, now a luminous intensity; but we will say that a length can be in the same ratio to a length as a mass to a mass or a luminous intensity to a luminous intensity; and this same ratio is the same number and can be signified by the same numeral. (Ibid., 2:85)

According to this Fregean idea, the ratio of the area of the earth's surface to the area of the northern hemisphere is identical to the real number two. In the sentence asserting that the height of the door is $2 \mathrm{~m}$, the numeral " 2 " refers to 
the ratio of the height of the door to the length of the standard meter, and this ratio, again, is the number 2 .

It might at first sight seem a shortcoming of Frege's approach that it explains numbers in terms of ratios and magnitudes, which might themselves be considered mathematical concepts. However, one can in fact define extensive magnitudes and their ratios without recourse to the concepts of real analysis, such that the resultant totality of ratios of extensive magnitudes becomes identifiable with the positive real numbers. Bob Hale (2000) has recently developed this Fregean idea in a rigorous manner, so allow me to just sketch the basic ideas. The core of this approach is to regard extensive magnitudes as concepts that can be introduced by abstraction from properties of concrete objects. To make this abstraction possible, it suffices to suppose that there are kinds of properties whose concatenation obeys certain principles (commutativity, associativity, strict trichotomy and the Archimedean axiom), which can all be defined and understood without any prior understanding of real analysis. Ratios can then in turn be abstracted from extensive magnitudes. Here, the idea is that the required identity condition (determining when two pairs of magnitudes exemplify the same ratio) can be formulated in terms of identities and inequalities of equimultiples of those magnitudes. In this way, real analysis can be built up from an understanding of concatenations of different magnitudes (e.g., regarding the mass of objects $A$ and $B$, considered together, as a function of the mass of object $A$ and object $B$ ) and multiple concatenations of the same magnitude. ${ }^{2}$

In contrast to this, the Helmholtzian approach does not imply that the number two in itself has anything to do with either masses, lengths and the like, or their ratios. Numbers, or rather numerals, are only employed to represent magnitudes. They are only put into this service by means of the use we make of

2 This identity condition and the Archimedean axiom make use of multiple concatenations of magnitudes, and therefore seem to presuppose arithmetic. While this seems to have been Frege's own view (see e.g. 1962 [1893/1903], 2:160 ff.), it might be interesting to note that the conditions require no more than an understanding of expressions of the form " $n \times a^{\prime}$, where $n$ is a numeral and $a$ an extensive magnitude. Presupposing no more than an ability to cope with numerals and their successor function $\sigma$, one can define recursively: $1 \times a=\mathrm{df} a$ and $\sigma(n) \times a=\mathrm{df}(n \times a) \oplus a$. (where “ $\Theta$ " represents the concatenation function on the respective magnitude kind). The identity condition for ratios could be formulated as follows: The ratio of magnitude $a$ to magnitude $b=$ the ratio of magnitude $c$ to magnitude $d$ if and only if for all pairs of numerals $n, m:[(m \times a=n \times b$ iff $m \times c=n \times d)$ and $(m \times a<n \times b$ iff $m \times c<n \times d)$ and $(m \times a>n \times b$ iff $m \times c>n \times d)]$. The order relation <is definable as $a<b \equiv \mathrm{df} \exists x: a \oplus x=b$. The feasibility of this definition is ensured by the aforementioned condition of strict trichotomy, which demands that for every pair of magnitudes of a given extensive magnitude kind, exactly one of the three following conditions holds: Either $a=b$, or there is a magnitude $c$, such that $a \oplus c=b$, or there is a magnitude $c$, such that $b \oplus c=a$. This implies that there are neither vanishing (or "zero") nor inverse (or "negative") extensive magnitudes in our present sense. 
them in our practices of measurement. This theory of the application of real analysis was later elaborated by Norman Campbell (1957 [1920])) and also largely adopted by the Logical Empiricists, e.g. by Carl Hempel (1952), by Ernest Nagel (1961), as well as by Carnap (1966). Again, this theory of real numbers as mere representational devices is not reductive, while Frege's approach strives to identify each real number with something that secures its applicability to extra-mathematical reality.

Frege's fragmentary theory of real numbers thus suggests the following answer to the question: "Why is real analysis applicable?"

(R-F) Real analysis is applicable because it is a body of truths about ratios of extensive magnitudes.

Going slightly beyond what Frege himself explicitly says, one might extend this explanation:

$(\mathrm{R}-\mathrm{F}+)$ Real analysis is applicable because it is a body of truths about ratios of extensive magnitudes, and ratios of extensive magnitudes happen to abound in the world we inhabit, where they play decisive roles in all kinds of events and regularities.

Have we come full-circle, back to the "platonizing view" scolded by Hahn, that the world is constructed according to the laws of logic and mathematics? The difference is that $(\mathrm{R}-\mathrm{F}+)$ incorporates the idea that the truths of real analysis can be abstracted from certain properties of concrete objects. The abstraction presupposes that these properties obey certain principles, and therefore real analysis will only provide us with immediately useful knowledge insofar as there are in fact some properties that do obey these principles and can therefore be considered extensive magnitudes. It is therefore only in a very partial and restricted sense that real analysis gives us a means to "grasp the eternal laws of the world", as Hahn's bogey platonist would claim. Neo-Fregeans will be keen to explain that whatever grasp of reality real analysis has, it has solely in virtue of its successful employment of abstraction principles. Alternatively, albeit in a decidedly less Fregean spirit, one might also refer to the considerable empirical import that is incorporated in such conceptions as multiple concatenations of extensive magnitudes. But this point cannot and need not be debated here, since we are chiefly interested in the fate of the applicability problem.

As regards the explanatory force of $(\mathrm{R}-\mathrm{F}+)$ with respect to the applicability problem, it is not instrumental whether the truths about ratios of extensive magnitudes are in any sense logical truths. All that matters is that the usefulness of the concepts of extensive magnitudes and their ratios for the description of physical reality is immediately explainable, in a way that the usefulness of numbers is not. 
$(\mathrm{R}-\mathrm{F}+)$ thus indicates why real numbers are useful for at least some physical applications. It thereby certainly suggests an explanation of the applicability of real analysis that is not included in the representational approach of Helmholtz, Campbell and latter day Logical Empiricism. Their account only details how real numbers can be used as representational instruments.

The case of real analysis thus shows that the reductive element in reductive logicism makes an important contribution to one aspect of the applicability problem, namely the question why mathematics is useful for many applications. What is essential is that Frege identifies mathematical concepts with something that clarifies the connection of analysis with its realm of application. The basis of this reduction is in effect provided by the conceptual resources that are required to understand multiple concatenations of extensive magnitudes. Now is this reductive basis itself "purely logical" or even "non-mathematical" in any rigorous sense? For the applicability problem, this question is not the decisive one. What matters is that $(\mathrm{R}-\mathrm{F}+)$ provides a conceptual connection between real numbers and masses, lengths, energies and other extensive magnitudes, and therefore provides a starting-point for an explanation of its usefulness for the description and explanation of natural phenomena. Conceiving of the number three as a certain ratio of extensive magnitudes is helpful in understanding why this mathematical concept figures at all in the description of, say, the design of a bridge-and this helpfulness is quite independent of the question whether or not the concepts of extensive magnitudes and their ratios can in turn be considered "logical". ${ }^{3}$

When Carnap and the Logical Empiricists chose to preserve the logicist tenets of reductive logicism, sacrificing its reductive elements, they made a decision that brought with it gains and losses. While it secured the logicist's answers to questions about the general character of mathematical truths, it forfeited the potential to account for the usefulness of mathematics in the sciences. This explanatory problem, which had been a major concern for the early logicists, was relegated to the realm of practical questions and thus excluded from the sphere of sensible theoretical discussion.

It is most interesting that this decision was not reversed when shortly afterwards Logical Empiricism began to fall on hard times. After all, it was primarily the reliance on the concept of analyticity that was getting the received view into trouble. Nevertheless, the problem of applicability did not re-emerge in post-positivist philosophy of science until fairly recently. (Cf. Hellman 1989, Steiner 1998, Pincock 2004, Wilholt 2004.) Why it took such a long time to

3 In my judgment, Frege's conception of real numbers can be incorporated within a systematic explanation of the applicability of real analysis that is independent of logicism or neologicism. Cf. Wilholt 2004, esp. ch. 5. 
rediscover the problem is a different question. However, the preceding reflections explain how it first came to fall into philosophical oblivion. Its relegation from theoretical discussion was the price for the development of a sustained version of Carnapian Logical Empiricism.

\section{References}

Ayer, Alfred Jules 1971 [1936]: Language, Truth and Logic, London: Penguin.

Bird, Graham 2003: 'Carnap's Internal and External Questions', in: Language, Truth and Logic, ed. by Thomas Bonk, Dordrecht: Kluwer, 97-131.

Campbell, Norman R. 1957 [1920]: Foundations of Science, [unaltered reissue of Physics: The Elements], New York: Dover 1957.

Carnap, Rudolf 1929: Abriss der Logistik mit besonderer Berücksichtigung der Relationstheorie und ihrer Anwendungen, Wien: Springer.

Carnap, Rudolf 1930: 'Die Mathematik als Zweig der Logik', Blätter für Deutsche Philosophie 4, 298-310.

Carnap, Rudolf 1967 [1934]: The Logical Syntax of Language, transl. Amethe Smeaton, London: Routledge \& Kegan Paul.

Carnap, Rudolf 1956 [1950]: 'Empiricism, Semantics and Ontology', in: Meaning and Necessity, enl. ed., Chicago \& London: University of Chicago Press, 205221.

Carnap: Rudolf 1966: Philosophical Foundations of Physics, ed. by Martin Gardner, New York: Basic Books.

Frege, Gottlob 1980 [1884]: The Foundations of Arithmetic, transl. J.L. Austin, Oxford: Blackwell.

Frege, Gottlob 1962 [1893/1903]: Grundgesetze der Arithmetik, 2 vols., reprint in one vol., Hildesheim: Olms.

Hellman, Geoffrey 1989: Mathematics Without Numbers, Oxford: Oxford University Press.

Hale, Bob 2000: 'Reals by Abstraction', Philosophia Mathematica (3) 8, 100-123.

Hahn, Hans 1988 [1933]: 'Logik, Mathematik und Naturerkennen', in: Hans Hahn: Empirismus, Logik, Mathematik, ed. by Brian McGuinness, Frankfurt a.M.: Suhrkamp, 141-172.

Helmholtz, Hermann von 1971 [1887]: 'Zählen und Messen, erkenntnistheoretisch betrachtet', in: Hermann von Helmholtz, Philosophische Vorträge und Aufsätze, ed. by Herbert Hörz und Siegfried Wollgast, Berlin: Akademie Verlag, 301-355.

Hempel, Carl G. 1952: Fundamentals of Concept Formation in Empirical Science, Chicago: University of Chicago Press. 
Hilbert, David 1992 [1919/20]: Natur und mathematisches Erkennen: Vorlesungen, gehalten 1919-1920 in Göttingen, ed. by D.E. Rowe, Basel: Birkhäuser.

McGuinness, Brian (ed.) 1987, Unified Science, Dordrecht: Reidel.

Nagel, Ernest 1961: The Structure of Science: Problems in the Logic of Scientific Explanation, New York etc.: Harcourt, Brace \& World.

Pincock, Christopher 2004: 'A New Perspective on the Problem of Applying Mathematics', Philosophia Mathematica (3) 12, 135-161.

Richardson, Alan 1994: 'The Limits of Tolerance: Carnap's Logico-Philosophical Project in Logical Syntax of Language', Proceedings of the Aristotelian Society, Supplementary Volume 68, 67-82.

Russell, Bertrand 1993 [1919]: Introduction to Mathematical Philosophy, reprint, London \& New York: Routledge.

Steiner, Mark 1998: The Applicability of Mathematics as a Philosophical Problem, Cambridge (Massachusetts): Harvard University Press.

Wilholt, Torsten 2004: Zahl und Wirklichkeit: Eine philosophische Untersuchung über die Anwendbarkeit der Mathematik, Paderborn: Mentis. 